\title{
Obesogenic environments in Ghana, the curse of 'modernity'
}

\begin{abstract}
Excess weight has been described by the World Health Organization (WHO) World Bank and the Centers for Disease Control and Prevention in the United States as the third highest risk factor in the affluent world and is within the top 10 risk factors in the regions of the world with the poorest people. Diabetes, heart disease, strokes, high blood pressure, cancers of the breast (post-menopause), colon and rectum, kidney and gallbladder disease are all risk associated with weight gain. Obesity has become a significant public health and a social problem in developing countries like Ghana already plagued with under nutrition and communicable diseases. Understanding the obesity epidemic and the need to find an immediate panacea remains gloomy due to the rapid rate of urbanisation, sedentary lifestyles due to technological advancements and changes in eating behaviours caused by the globalisation of food markets that has transformed the food systems of lower and middleincome countries. The influence of the modern Ghanaian environment on food intake, physical activity as well as the movement of people must be tackled using a multi-facet approach. Cultural and social environmental influence coupled with perceptions around availability, accessibility, and affordability of healthy food present enormous challenges on improving the Ghanaian environment to promote healthier choices. The need for inter sectoral collaboration within Government departments, civil society groups, and nongovernmental organisations in developing cross-government policies targeted primarily at ensuring that the Ghanaian populace makes healthy decisions.
\end{abstract}

Keywords: obesogenic environment, obesity, Ghana, sedentary lifestyle, noncommunicable diseases
Volume 5 Issue 3 - 2016

\section{Ernest Bonah}

Northern Regional Office, Food and Drugs Authority, Ghana

Correspondence: Ernest Bonah, Food and Drugs

Authority, Box TL 1763, Tamale, Northern Region, Ghana, Tel +233277273505 ,

Email bonerstgh@gmail.com,ernest.bonah@fdaghana.gov.gh

Received: November 21, 2016 | Published: November 28 2016

\section{Introduction}

The term "obesogenic environment" refers to "an environment that promotes gaining weight and one that is not conducive to weight loss" within the home or workplace. ${ }^{1}$ The obesogenicity of an environment 'the sum of influences that the surroundings, opportunities, or conditions of life have on promoting obesity in individuals or populations. ${ }^{2}$ Obesity is a medical condition in which excess body fat has accumulated to the extent that it may have an adverse effect on health. ${ }^{3}$ People are considered obese when their body mass index (BMI), a measurement obtained by dividing a person's weight by the square of his/her height, is over $30 \mathrm{~kg} / \mathrm{m}^{2}$, with the range $25-30 \mathrm{~kg} / \mathrm{m}^{2}$ defined as overweight. ${ }^{4}$

Obesity is a precursor to various diseases, particularly cardiovascular diseases, type 2 diabetes, certain types of cancer, osteoarthritis and obstructive sleep apnea. ${ }^{5}$ Worldwide Obesity prevalence has doubled since 1980 with the World Health Organisation (WHO) estimating 1.5 billion adults being overweight with 300 (females) and 200 (males) million being obese in 2010. Diet-related no communicable diseases (NCDs) is a huge public health concern Sub-Saharan Africa with a high prevalence of diabetes, cancer and heart diseases. The causality of obesity is positively correlated to rapid urbanisation, changes in our food supplies, increasing life expectancy and sedentary lifestyles.

The prevalence of Obesity in Ghana is on the rise since 1993 and pose a significant health and an economic challenge as a country. Literature suggests females, urban dwellers, the highly educated, the wealthy and married people have higher levels of obesity while, rural dwellers, the less educated and unmarried people have lower levels of obesity. ${ }^{6}$
The obesity epidemic is highly dependent on energy balance, diet (energy in) and physical activity (energy out).Rural -urban migration is on the rise astronomically with more than half of the population leaving in urban areas. According to the Population Division of the UN Department of Economic and Social Affairs (DESA) reports rapid urbanisation in Ghana over the last five decades. The Table 1 below shows Ghana's urban growth rate.

Table I Percentage growth of Ghanaians leaving in urban areas

\begin{tabular}{llll}
\hline Year & 1960 & 2000 & 2010 \\
\hline Growth\% & 23 & 43.8 & 51.5 \\
\hline
\end{tabular}

This growth has led to substantial developmental challenges and the increased growth in the number of slums and squatter settlement, especially in the two most populous cities, Accra and Kumasi. The lack of physical and social infrastructure to accommodate the influx of migrants has led to the clamouring for land space and the conversion of recreational lands such as football fields and walkways into housing and informal market infrastructures. Urbanisation has also mechanised society thus reducing the need for physical work. The use of vehicles for transport as a result of increased technological developments of our physical and social environments has minimised the need for physical activity. Globalisation of world food markets has led to changes in food consumption patterns in Ghana. ${ }^{7}$ Obesity is as a result of a multiplicity of factors including urbanisation, rapid nutritional transition and adoption of western lifestyles. ${ }^{8}$ In Ghana, having a large body size is associated with affluence and a sign of healthier living. It is also culturally acceptable and favoured as opposed to being slim. ${ }^{9}$ Obesity is more prevalent amongst educated people and has shown a 
positive correlation with the socioeconomic status of Ghanaians. The probability of been obese is directly proportional to the socioeconomic status of an individual. ${ }^{10}$

Urbanisation impacts negatively on physical activity and increases food supply from global food chains. The phenomenon of fast foods and outdoor eating has exposed urban dwellers to high-calorie diets and sugar-sweetened beverages. The study on the characteristics of the physical environment and its impact on obesity has been investigated extensively over the last decade. ${ }^{11-14}$ Urban sprawl and the proximity to fast food outlets and restaurants is likely to encourage sedentary lifestyles and cause obesity. ${ }^{15}$ The marketing of sugar drinks and its related products in developing countries like Ghana is on the increase. The consumption of these products is often associated with affluence soaring the rates of obesity, diabetes, tooth decay and other associated health problems.

Driving consumption and obesity rates upward are massive food marketing campaigns. This celebrity studded advertising campaigns is mainly targeted at young children and teenagers. The powerful marketing and distribution of sugar-sweetened beverages create obesogenic environments in which people consume more calories and gain weight. ${ }^{16,17}$ Traditional TV advertising, video games, billboards and point-of-sale advertising are designed to increase brand recognition, appeal, and ultimately purchase of sugar-sweetened beverages. In Ghana, the marketing of sugar-sweetened beverages is seen in and around most schools in the country. Large billboards advertising junk foods and providing signage for schools are dotted all over the country. Most educational programs and competitions for students have been sponsored by these companies. In effect, the schools are endorsing the beverages.

Fast food marketing coupled with affluence associated with eating at these fast food joints has rapidly increased the rate of consumption of high-calorie diets and junk foods. ${ }^{18,19}$ Research suggest that for every US\$1 spent by the WHO to improve nutrition, the food industry spends US\$500 in promoting processed foods. ${ }^{20}$ Although there has been rising concerns and public health campaigns on the need to consume fruits and vegetables, affordability and availability of fresh fruit and vegetables over sugar-sweetened beverages, energy drinks are very low. However, it must be noted that some sugar-sweetened beverage companies are beginning to develop sugar-free or reduced sugar products with some natural ingredient. ${ }^{21}$

Developing countries like Ghana with growing incomes is in a state of rapid nutrition transition where traditional diets rich in fruits, vegetables, fibres and grains are replaced with so-called modern and affluent diets rich in fats, and caloric sweeteners. ${ }^{22}$ Together with our newly built environment that discourages physical activity can lead to serious health consequences.

\section{Conclusion}

The need for a holistic policy approach to help prevent obesity and NCDs through a multisectoral approach is highlighted by WHOs 2013-2020 global action plan. Ghana must take huge steps at reducing obesity and improving the nutritional behaviour of its growing urban population. Obesity in young children and adolescents must be of particular interest to public health officials. Various studies suggest teenagers who are obese will continue to be so throughout their adult life exposing them to serious health risk. ${ }^{23}$

Ghana's Food environment and built environment must be studied extensively; the intricate synergy between these two environments has the potential of providing solutions to our rising obesity epidemic.
The environmental determinants of food availability, physical activity and obesity.

There is a need for a closer association and relationship between public health officials and professionals who are involved in town planning, housing and transportation systems.

Behaviour change at the individual level is also required as a measure in tackling the obesity epidemic.

\section{Acknowledgements}

None.

\section{Conflict of interest}

Author declares that there is no conflict of interest.

\section{References}

1. Swinburn BA, Egger GJ, Raza F. Dissecting obesogenic environments: the development and application of a framework for identifying and prioritising environmental interventions for obesity. Prev Med. 1999;29(6 Pt 1):563-570.

2. Obesity and overweight Fact Sheet.

3. What is childhood obesity?

4. Fat men are likely to live longer.

5. Haslam DW, James WP. Obesity. Lancet. 2005;366(9492):1197-1209.

6. Amoah GBA. Socio-demographic Variations in Obesity among Ghanaian Adults. Public Health Nutrition. 2003;6(8):751-757.

7. Amelia A Lake, Tim G. Townshend Seraphim Alvanides. 2010.

8. Dinsa GD, Goryakin Y, Fumagalli E, et al. Obesity and socioeconomic status in developing countries: a systematic review. Obes Rev. 2012;13(11):1067-1079.

9. Ojofeitimi EO, Adeyeye AO, Fadiora AO, et al. Awareness of obesity and its health hazard among women in a University community. PJN. 2007;6(5):502-505

10. Duda R, Jumah NA, Hill AG, et al. Assessment of the ideal body image of women in Accra, Ghana. Trop Doct. 2007;37(4):241-244.

11. Neuman M, Kawachi I, Gortmaker S, et al. Urban-rural differences in BMI in low- and middle-income countries: the role of socioeconomic status. Am J Clin Nutr. 2013;97(2):428-436.

12. Feng J, Glass TA, Curriero FC, et al. The built environment and obesity: a systematic review of the epidemiologic evidence. Heal Place. 2009;16(2):175-190.

13. Durand CP, Andalib M, Dunton GF, et al. A systematic review of built environment factors related to physical activity and obesity risk: implications for smart growth urban planning. Obes Rev. 2011;12(5):e173-e182.

14. Sallis JF, Floyd MF, Rodríguez DA, et al. Role of built environments in physical activity, obesity, and cardiovascular disease. Circulation. 2012;125(5):729-737

15. Ding D, Gebel K. Built environment, physical activity, and obesity: what have we learned from reviewing the literature. Heal Place. 2012;18(1):100-105.

16. Holsten JE. Obesity and the community food environment: a systematic review. Public Heal Nutr. 2009;12(3):397-405.

17. Te Morenga L, Mallard S, Mann J. Dietary sugars and body weight: systematic review and meta-analyses of randomised controlled trials and cohort studies. BMJ. 2013;346:e7492. 
18. Malik VS, Pan A, Willett WC, et al. Sugar-sweetened beverages and weight gain in children and adults: a systematic review and metaanalysis. Am J Clin Nutr. 2013;98(4):1084-1102.

19. Prentice AM, Jebb SA. Fast foods, energy density and obesity: a possible mechanistic link. Obesity Reviews. 2003;4(4):187-194.

20. Popkin BM, Duffey K, Gordon-Larsen P. Environmental influences on food choice, physical activity and energy balance. Physiol Behav. 2005;86(5):603-613.
21. Wiist WH. The bottom line or public health: Tactics corporations use to influence health and health policy, and what we can do to counter them. USA: Oxford University Press; 2010.

22. Drewnowski A, Popkin B. The nutrition transition: New trends in the global diet. Nutrition Reviews. 1997;55(2):31-43.

23. BMA. Adolescent Health. British Medical Association Board of Science and Education. 2003:1-66. 